\title{
Obituary
}

\section{Professor Om Prakash Sharma}

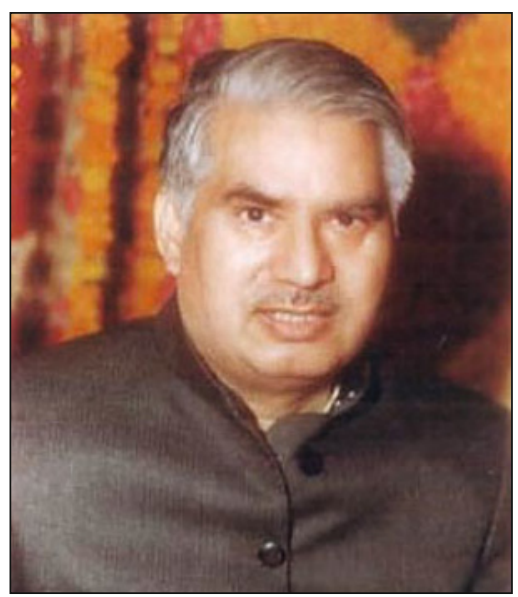

Professor Om Prakash Sharma (1933-20II)

Professor O.P. Sharma was born on October 1, 1933 in a village called Pala Asi in Distt. Aligarh of Uttar Pradesh. He graduated from Gajra Raja Medical College, Gwalior, India, with distinctions and joined King George Medical College, Lucknow, India, for MS orthopedics under Prof. B N Sinha and cleared M.S. (Orthopedics) in the first attempt (1957).

He initially joined Christan Medical College, Vellore, India, as a junior lecturer. Later on he joined Gajra Raja Medical College, Gwalior, as a Lecturer in orthopedics. He was promoted to the post of reader (1964) and transferred to Gandhi Medical College, Bhopal where he spent rest of his life.

He was instrumental in establishing Orthopedics as a specialty in Madhya Pradesh. The Orthopaedics Department was separated from general surgery in 1968 and he became the first Head of the Department in Orthopaedics at Gandhi Medical College, Bhopal, India. He was promoted to the post of Professor (1972) and became the first director of Artificial Limb Centre (1982). He also worked as a dean at Gandhi Medical College, Bhopal from 1985 to 1988. On September 30, 1993 he retired from the post of Professor and Head of Orthopaedics, Gandhi Medical College, Bhopal, and was given one of the best farewell in the history of Gandhi Medical College, Bhopal, a farewell in which almost all students from all over the state and country attended.

He established the Madhya Pradesh chapter of Indian Orthopaedic Association in 1981 and was the founder president of the association. He served as the Vice-President of Indian Orthopaedic Association. To honor this PITAMAH of Orthopaedics Dr. O.P. Sharma Oration was started by the M.P. chapter of IOA in 2001. He was conferred the life time achievement award by IOA in 2009.

He was very soft spoken and had a charismatic personality. Clubfeet tendon transfer and spine surgery were his favorite. He was famous among his students for conveying a lengthy message in a few words and grooming as a complete human being. Almost all district hospitals and medical colleges in Madhya Pradesh, India, have orthopedic surgeons taught by him.

He is survived by his wife and two daughters (Dr. Seema Sharma and Dr. Pratima Sharma) and one son (Dr. Sandeep Sharma) who is also an Orthopaedic surgeon and is carrying on the legacy of his father.

May his soul rest in peace.

Nirbhay Shrivastava

Dean Gandhi Medical College, Bhopal, India E-mail:nirbhay_48@yahoo.co.in

\begin{tabular}{|l|l|}
\hline \multicolumn{2}{|c|}{ Access this article online } \\
\hline Quick Response Code: & \\
\hline & Website: \\
\hline
\end{tabular}

